\title{
The Use of a Colloidal Silica Preparation in Media Used for Yeast Identification
}

\author{
By R. W. M. BUHAGIAR \\ Agricultural Research Council Food Research Institute, Colney Lane, \\ Norwich $N_{4}{ }_{7} U A$
}

(Received 7 September 1976)

\begin{abstract}
SUMMARY
Nutritional tests on yeasts which utilize myo-inositol as the sole carbon source or which have red pigment have been carried out on defined media solidified with silica gel (Ludox HS-40) in multicompartment polystyrene dishes. Yeasts of the above types isolated from soft fruits were tested together with I89 named strains representing 28 genera and IIO species and varieties. The results obtained were compared with those for growth on media solidified with several commercially prepared agars. Methods are described for purifying commercial samples of Ludox HS-40 and for removing contaminating sugars from some di-and trisaccharides used in the tests.
\end{abstract}

\section{INTRODUCTION}

In surveys of yeasts obtained from soft fruits, carried out between 1968 and 1975, over $80 \%$ of the isolates utilized myo-inositol as the sole carbon source or formed rugose colonies. Yeast species showing either of these two characteristics can be identified by their ability to utilize nine sugars as sole carbon sources, and nitrate as the sole nitrogen source, and by their ability to form starch, ballistospores or grow filamentously. This paper describes a simplified method for accurately testing the carbon and nitrate utilizing properties of these species on media gelled with Ludox HS-40, a commercial colloidal silica solution.

\section{METHODS}

Estimation of D-glucose and D-fructose contamination in commercially supplied sugars. D-glucose contamination in solutions of raffinose, melezitose, sucrose and maltose was estimated by the hexokinase/glucose-6-phosphate dehydrogenase method of Slein (1963). The D-fructose present in melezitose, sucrose and raffinose was subsequently estimated using phosphoglucose isomerase (Klotzsch \& Bergmeyer, 1963).

Freshly made solutions of commercially supplied maltose contained up to $\mathrm{I} \%(\mathrm{w} / \mathrm{w})$ D-glucose, and melezitose contained up to $0.7 \%$ D-glucose and $0.3 \%$ (w/w) D-fructose. In sucrose, the total contamination with D-glucose plus D-fructose was less than $0.02 \%$, and raffinose contained less than $0.03 \%$ D-fructose. No increase in the level of contamination was observed in aqueous solutions of maltose or melezitose ( $\mathrm{pH} \mathrm{5.6)} \mathrm{shaken} \mathrm{for} 26$ days at $20{ }^{\circ} \mathrm{C}$. In similar sucrose solutions, however, $0.06 \% \mathrm{D}$-glucose and $0.06 \% \mathrm{D}$-fructose were present after 7 days shaking at $20{ }^{\circ} \mathrm{C}$, increasing to $0.2 \%$ of each sugar after 26 days incubation. Similarly, between 0.2 and $0.3 \%$ D-fructose was present in raffinose solutions shaken for 26 days at $20^{\circ} \mathrm{C}$. 


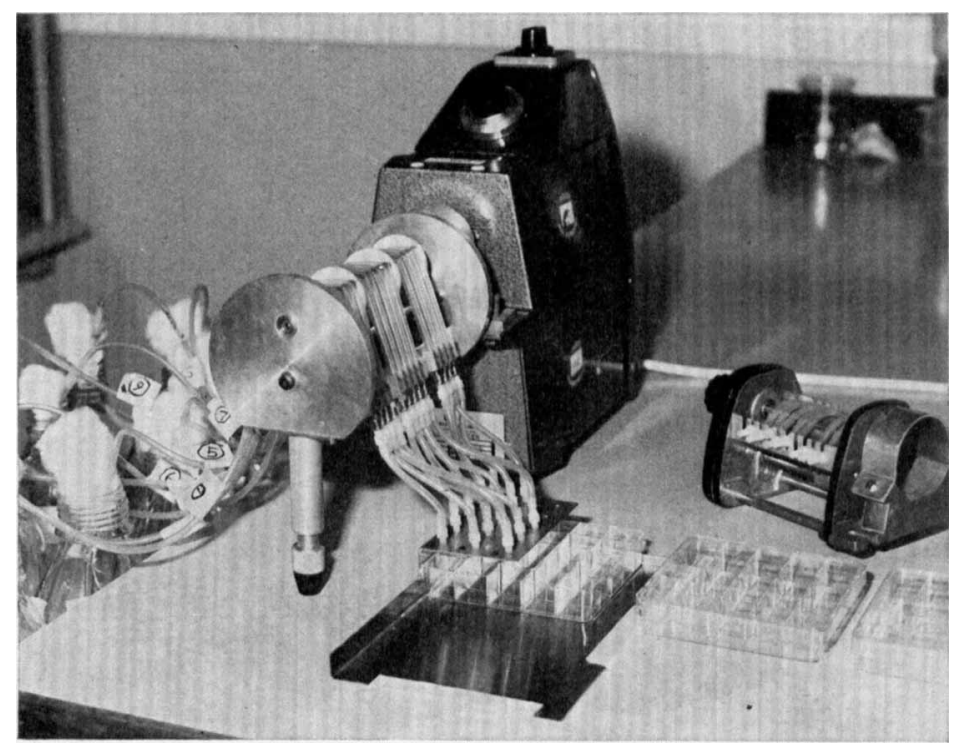

Fig. I. Apparatus for distributing media into Repli dishes. A Delta Micro-metering pump fitted with a specially constructed I5-tube module set to deliver I 3 portions of media simultaneously. To the right of the pump is a standard Delta 1o-tube module.

Removal of D-glucose and D-fructose from the sugar solutions. The D-glucose and D-fructose present in commercial supplies of melezitose, sucrose, maltose and raffinose were removed by incubating $200 \mathrm{~mm}$ solutions of these sugars with washed cells of Kloeckera apiculata, a yeast which is unable to utilize the four sugars concerned. Cells from cultures of $K l$. apiculata ( $\mathrm{NCYC} 328)$ grown on Difco Bacto-YM agar for 3 days at $20^{\circ} \mathrm{C}$ were washed twice with sterile distilled water and centrifuged at $4000 \mathrm{~g}$ for $10 \mathrm{~min}$; the supernatant was discarded. The washed cells were added to the sugar solutions and the cell concentration was adjusted to about $0.8 \mathrm{mg}$ dry wt yeast $\mathrm{ml}^{-1}$. The suspensions $(250 \mathrm{ml})$ were then incubated in 21 flasks on a rotary shaker ( $\left.150 \mathrm{rev} . \mathrm{min}^{-1}\right)$ for $\mathrm{I} 8 \mathrm{~h}$ at $25^{\circ} \mathrm{C}$. The yeast cells were removed by centrifuging at $4000 \mathrm{~g}$ for Io min followed by filtration through a $0.22 \mu \mathrm{m}$ pore size membrane (Millipore) and the purified sugar solutions were used immediately in the required media. The absence of D-glucose and $D$-fructose was checked by inoculating media containing the purified sugars with cultures of Kl. apiculata ( $\mathrm{NCYC} 328)$ and Torulopsis pustula (CBS6528), neither of which can utilize the four oligosaccharides.

Deionization of the Ludox HS-40 colloidal silica solution. An aqueous solution of Ludox HS-40 (75\%, v/v; Du Pont Co. (U.K.), London ECI) was passed at $4 \mathrm{ml} \mathrm{min}^{-1}$ through the cation exchanger Dowex 50W-X8 (hydrogen form; Dow Chemical Co., Michigan, U.S.A.) and then through the anion exchanger Amberlite IR-45 (hydroxyl form; Rohm \& Haas Co., Pennsylvania, U.S.A.). The resins were prewashed (Hirs, Moore \& Stein, I952; Steven \& Tristram, 1962) and packed into $500 \times 30 \mathrm{~mm}$ columns. Resin beds containing

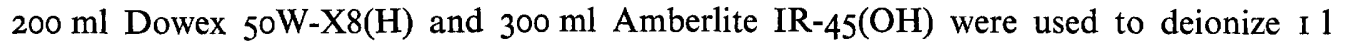
of $75 \%(\mathrm{v} / \mathrm{v})$ Ludox HS-40 solution.

Preparation and dispensing of the silica gel media. The media for testing the utilization of the carbon sources and of $\mathrm{KNO}_{3}$ were those used by Wickerham (I95I) except that the amino acids were omitted (Barnett \& Ingram, I955) and $50 \mathrm{~mm}$-carbon sources were added 
(Buhagiar \& Barnett, 1971). In the medium containing $\mathrm{KNO}_{3}$ as the sole nitrogen source, the concentration of $\mathrm{KH}_{2} \mathrm{PO}_{4}$ was increased to $5 \mathrm{~g} \mathrm{l}^{-1}$.

To make I 1 medium, Io $\mathrm{ml}$ of filter-sterilized vitamin solution was mixed aseptically with $250 \mathrm{ml}$ of a filter-sterilized $200 \mathrm{~mm}$ solution of the required carbon source (raffinose, melezitose, sucrose, maltose, lactose, erythritol, myo-inositol, L-rhamnose, melibiose or D-glucose) and with $200 \mathrm{ml}$ of a solution containing the appropriate mineral salts sterilized by autoclaving for $15 \mathrm{~min}$ at $12 \mathrm{I}{ }^{\circ} \mathrm{C}$. Deionized Ludox HS-40 solution $(533 \mathrm{ml})$, sterilized by autoclaving for $\mathrm{I} 5 \mathrm{~min}$ at $\mathrm{I} 2 \mathrm{I}{ }^{\circ} \mathrm{C}$, was then added and the volume was made up to I 1 with sterile distilled water. This silica gel medium was adjusted to $\mathrm{pH} 5.6$ with sterile $\mathrm{I} \mathrm{M}-\mathrm{HCl}$ or I $\mathrm{M}-\mathrm{NaOH}$.

A Delta Micro-metering pump (Watson-Marlow, Falmouth, Cornwall) fitted with a specially constructed I 5 -tube module (Fig. I) was used to deliver $3 \mathrm{ml}$ medium into individual compartments of polystyrene Repli dishes (Sterilin, Richmond, Surrey). The various test media were pumped simultaneously from the flasks through a series of silicone rubber tubes $(3 \mathrm{~mm}$ internal diam.), the ends of which were attached to stainless-steel nozzles inserted through a stainless-steel template that fitted on top of a Repli dish (Fig. I). The colloidal silica medium in the unvented Repli dishes gelled after $24 \mathrm{~h}$ at room temperature (about $20^{\circ} \mathrm{C}$ ). The prepared Repli dishes were inoculated within 3 days.

The chemicals used were obtained from BDH (AnalaR grade), and the sugars and vitamins were from Sigma.

Yeast inoculation of the silica gel media. The individual compartments of the Repli dishes containing the colloidal silica media were inoculated with an aqueous yeast suspension ( $30 \mu \mathrm{l}$; containing about $0.025 \mathrm{mg}$ dry wt yeast $\mathrm{ml}^{-1}$ ) obtained from a 2 to 3 -day-old culture growing at $20^{\circ} \mathrm{C}$ on Difco Bacto-YM agar. The inoculated dishes were incubated lid uppermost at $20^{\circ} \mathrm{C}$ for 7 days.

\section{RESULTS}

\section{Preliminary treatment of Ludox HS-4O silica solution}

Earlier tests showed that untreated Ludox HS-40 contained inhibitors since many of the yeasts grew poorly or not at all on medium containing over $6.5 \%$ ( $/ / v$ ) Ludox HS-40 $[2.6 \%(\mathrm{w} / \mathrm{v})$ silica content]. However, with $6.5 \%$ Ludox HS-40, medium containing the salt concentration used by Wickerham (1951) gelled only after lengthy periods. This delay could be reduced to about 2I days by increasing the $\mathrm{NaCl}$ and $\mathrm{KH}_{2} \mathrm{PO}_{4}$ content of the basal medium Io-fold. With a lower concentration of silica, the medium failed to gel. In contrast, no inhibition of yeast growth was observed on medium prepared with up to $40 \%$ deionized Ludox HS-40 [ $16 \%(\mathrm{w} / \mathrm{v})$ silica content], at which concentration the carbon and nitrate utilization media (see Methods) gelled after $24 \mathrm{~h}$. Similar results were obtained with five random samples of Ludox HS-40 supplied by Du Pont. After treatment with cationexchange resin, the $\mathrm{pH}$ of the five samples ( $75 \%$ aqueous solutions) was lowered from about Io to between $\mathrm{I} \cdot 6$ and $2 \cdot 8$. Subsequent treatment with anion-exchange resin raised the $\mathrm{pH}$ of these solutions to between 3.4 and 5.8 . After autoclaving ( $15 \mathrm{~min}$ at $12 \mathrm{I}{ }^{\circ} \mathrm{C}$ ) the $\mathrm{pH}$ of four of these solutions ranged from 7 to $7 \cdot 5$; the $\mathrm{pH}$ of the remaining solution was $5 \cdot 6$. No gelling occurred with any of these solutions although the solution at $\mathrm{pH} 5.6$ became progressively more viscous after storage for 3 months at room temperature. None of the solutions adjusted to $\mathrm{pH} 7$ before autoclaving showed any tendency to become glutinous on subsequent storage. 
Table I (a). Nitrate-positive strains tested

Yeast

Aessosporon salmonicolor Aureobasidium pullulans

A. prunorum

Brettanomyces anomalus Cryptococcus albidus var. albidus Cr. albidus var, aerius

Cr. albidus var. diffluens

Cr. infirmo-miniatus

Cr. kuetzingit

Cr. macerans

Cr. terreus

Hansenula anomala

H. saturnus

H. silvicola

H. subpelliculosa

H. wingei

Leucosporidium scottii

Oosporidium margaritiferum
Strain*

CBS5937

ATCCI 1942

FRI32

NCYC 449

LTS I9, FRI 58

CBSr55

$\mathrm{NCYC}_{4} 60$

FRI50

CBSI926

FRI59, NCYC 586

$\mathrm{NCYC}_{393}$

CBS 2577

$\mathrm{NCYC}_{22}$

$\mathrm{NCYC}_{413}$

NCYCI6

NCYC809, NCYC810

FRI13

FRI24

\begin{tabular}{ll}
\multicolumn{1}{c}{ Yeast } & \multicolumn{1}{c}{ Strain* } \\
Rhodosporidium capitatum & FRI55 \\
Rhodotorula glutinis & NCYC59 \\
Rh. lactosa & CBS5826 \\
Sporidiobolus johnsonii & CBS 522.50 \\
Sporobolomyces holsaticus & NCYC420 \\
Sp. odorus & CBS483 \\
Sp. roseus & NCYC423 \\
Torulopsis bacarum & CBS6526, FRI4I \\
T. domercqii & IGC3067 \\
T. fragaria & CBS6253, FRI53 \\
T. magnoliae & IGC352, IGC3191 \\
T. pustula & CBS6527, CBS6528 \\
Trichosporon pullulans & FRI55, FRI47, \\
& CBS5108, CBS2532, \\
& CBS2534, CBS2535, \\
& CBS2536, CBS2538, \\
& CBS2539, CBS2540, \\
& CBS254I, CBS2542
\end{tabular}

Table I (b). Nitrate-negative strains tested

Yeast

Aessosporon dendrophilum

Bullera alba

Candida curvata

C. diddensii

C. humicola

C. krusei

C. lambica

C. mesenterica

C. parapsilosis

C. tropicalis

C. valida

C. zeylanoides

Cryptococcus ater

Cr. dimennae

Cr. flavus

Cr. gastricus

Cr. hungaricus

Cr. lactativorus

Cr. laurentii var, laurentii

Cr. laurentii var. flavescens

Cr. laurentii var. magnus

Cr. luteolus

Cr. melibiosus

Cr. skinneri

Cr. uniguttulatus

Debaryomyces hansenii

D. marama

Filobasidium capsuligenum

Hanseniaspora valbyensis

Kloeckera africana

Kl. apiculata

Kluyveromvces dobzhanskii

$K$. drosophilarum

$\boldsymbol{K}$. fragilis

K. lactis

\section{K. marxianus}

Lipomyces starkeyi Metschnikowia pulcherrima

Nadsonia elongata

Pichia burtonii

$P$. delftensis

$P$. fermentans

P. kudriavzevii

$P$. membranaefaciens

$P$. pastoris

$P$. pinus

$\boldsymbol{P}$. rhodanensis

P. trehalophila

P. vini

$\quad$ Yeast
Rhodotorula minuta
Rh. rubra
Saccharomyces bailii var. bailii
S. bailii var. osmophilus
S. bisporus var. bisporus
S. cerevisice

S. eupagycus

S. fermentati

S. florentinus

S. kluyveri

S. rosei

S. rouxii

S. uvarum

Saccharomycodes ludwigii

Saccharomycopsis capsularis

Saccharomycopsis lipolytica

Schizosaccharomyces octosporus Schiz. pombe

Sporobolomyces pararoseus Torulopsis candida

$T$. colliculosa

$T$. inconspicua

T. mult is-yemmis

T. xestobii

Trichosporon aculeatum

Tr. capitatum

Tr. cutaneum
Strain*

FRI38, FRI39

$\mathrm{CBS}_{316}$, NCYCI42

CBS749, ATCC2602

DBDR 58

NCYC17I

FRII, CBS2823,

$\mathrm{NCYC}_{77}, \mathrm{NCYC}_{78}$,

NCYC81, NCYC89,

NCYC93, NCYCI14,

NCYC176, NCYC23I,

NCYC365, NCYCi026,

NCYCr14I, NCYCr235,

NCYCi $244, L_{22}$

CBS748

CBS818

$\mathrm{CBS}_{746}, \mathrm{NCYC}_{172}$

NCYC616

CBS728

NCYC568, ATCC 4898

$\mathrm{NCYC}_{74}, \mathrm{NCYC}_{324}$,

$\mathrm{NCYC}_{354}, \mathrm{NCYC}_{463}$,

NCYC534

NCYC52I

NCYC1 27

FRI8, IGC 3345 ,

IGC3346

NCYCI3I

CBS2627, NCYC132

$\mathrm{NCYC}_{3} 80$

$\mathrm{CBS}_{484}$

FRII7, FRII8,

$\mathrm{NCYC}_{3} 89, \mathrm{NCYC} 576$

NCYCI4I

FRII9

CBS6524, CBS6525

CBS5975

$\mathrm{CBS}_{5578}$

$\mathrm{NCYC}_{473}$

FRI23, FRI54

CBS2485, CBS2486,

CBS2488, CBS2489,

CBS2493, CBS2545,

CBS2820, CBS5785,

$\mathrm{NCYC}_{444}, \mathrm{NCYC}_{472}$

FRI37, CBS2529

CBS5585

CBS5586

* FRI, Food Research Institute; CBS, Centraal Bureau voor Schimmelcultures; NCYC, National Collection of Yeast Cultures; ATCC, American Type Culture Collection; LTS, Department of Scientific and Industrial Research, Low Temperature Pesearch Station; IGC, Instituto Gulbenkian de Ciencia; DBDR, Division of Bacteriology and Dairy Research Service. 
(a)

(b)

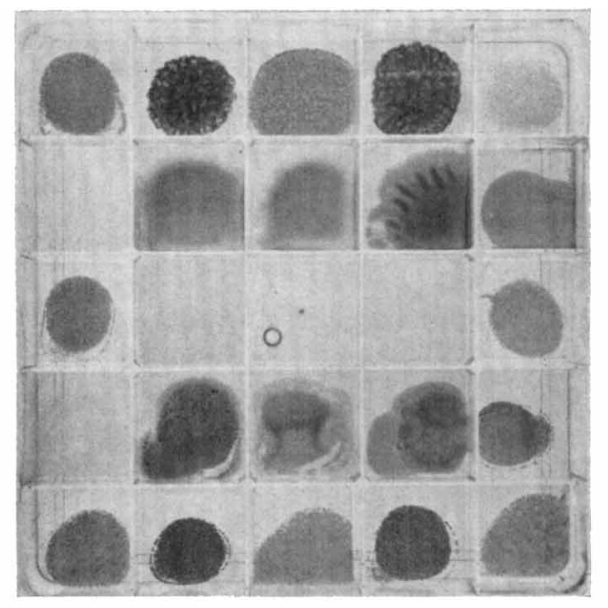

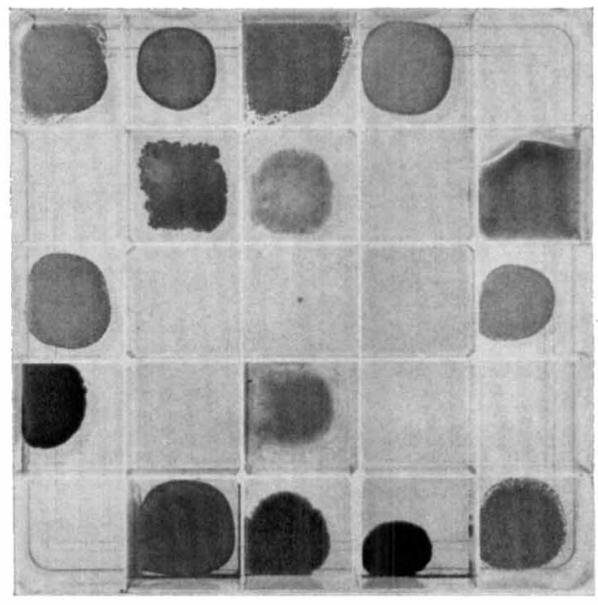

$(d)$

(c)

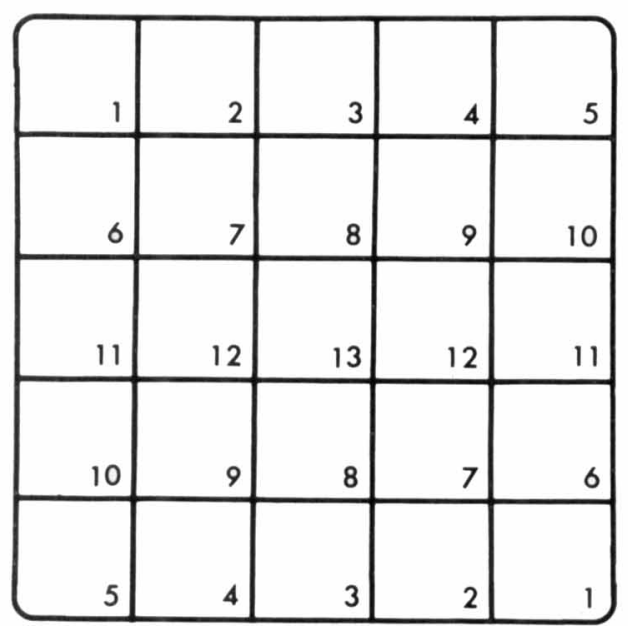

Fig. 2. Growth of yeasts on media gelled with Ludox HS-40. (a) Cryptococcus albidus var. albidus, (b) Cr. laurentii var. laurentii, (c) Cr. infirmo-miniatus (rugose yeast) and $(d)$ Rhodotorula glutinis (rugose yeast) growing in Repli dishes filled with basal utilization medium gelled with Ludox HS-40 and containing: (I) raffinose; (2) melezitose; (3) sucrose; (4) maltose; (5) lactose; (6) erythritol; (7) myo-inositol; (8) L-rhamnose; (9) melibiose; (10) D-glucose with $\mathrm{KNO}_{3}$ as sole nitrogen source; (I I) D-glucose; (I 2) D-glucose and no added nitrogen source; (I3) no added carbon source. The Repli dishes were incubated at $20^{\circ} \mathrm{C}$ for 7 days.

\section{Purity of the treated melezitose, sucrose, maltose and raffinose}

After incubation for 26 days at $20{ }^{\circ} \mathrm{C}$ with Kl. apiculata (NCYC328) or T. pustula (CBS6528), no growth occurred in freshly made liquid defined media (Wickerham, I95I) without amino acids and containing $50 \mathrm{~mm}$ purified maltose or melezitose solutions. However, the continuing production of constituent monosaccharides from the purified sucrose and raffinose was sufficient to support traces of growth with the same two species after 7 days incubation at $20^{\circ} \mathrm{C}$. With further incubation this growth progressively intensified. 


\section{Carbon and nitrate utilization tests}

Tests carried out with I 89 yeasts (Table I) representing 28 genera showed that after incubation for 7 days at $20^{\circ} \mathrm{C}$ growth on the carbon utilization medium containing D-glucose and on the $\mathrm{KNO}_{3}$ utilization medium, both gelled with the deionized Ludox HS-40 solution, was generally comparable with that obtained on similar media gelled with $\mathrm{I} \cdot 5 \%$ (w/v) of either Agarose (Sigma), Special Agar-Noble (Difco), Ionagar no. 2 (Oxoid), washed Ionagar no. 2 (Oxoid), washed New Zealand Agar (Davis), Bacto-Agar (Difco) or Purified Agar (Oxoid). There was limited growth on both the agar and the Ludox HS-40 media of Trichosporon cutaneum (NCYC444; CBS2486), Saccharomycodes ludwigii (NCYC52 I), Kloeckera africana (NCYC58), Saccharomycopsis capsularis (NCYCI 27), Schizosaccharomyces pombe (NCYC380), Torulopsis xestobii (CBS5975), and Cr. albidus var. aerius (CBSI55). Growth with Tr. cutaneum (CBS2486; CBS2545; NCYC444) and with Cr. laurentii var. laurentii (NCYCI39) was noticeably more abundant on the Ludox HS-40 medium. Of the yeasts isolated from fresh fruit surveys, I 73 were grown on the Ludox HS-40 media with the appropriate carbon sources (see Methods). These included $\mathrm{Cr}$. laurentii var. flavescens, $\mathrm{Cr}$. laurentii var. laurentii, Cr. albidus var. albidus, Cr. albidus var. diffluens, Cr. macerans, Cr. infirmo-miniatus, Rhodotorula glutinis and Sporobolomyces roseus, together with named species and varieties of the genera Cryptococcus, Rhodotorula, Rhodosporidium, Sporobolomyces and Sporidiobolus (Table I). Growth was clearly differentiated after 7 days at $20^{\circ} \mathrm{C}$ (Fig. 2). Yeast growth on carbon utilization medium containing no sugar and gelled with silica, was absent or minimal after incubation for 7 days at $20^{\circ} \mathrm{C}$. In contrast, there was often limited growth with the same basal medium gelled with the seven types of agar tested. Of the various types, Oxoid Purified Agar and the laboratory washed agars showed least organic impurities capable of sustaining yeast growth. Similarly, with the nitratenegative yeasts tested (Table I), less growth was encountered on the silica/ $/ \mathrm{NO}_{3}$ medium than with the same medium gelled with the seven agars tested. Incidental growth supported by the nitrogen introduced by the cell inoculum (Thorne, 1945) can be minimized by reducing the concentration of the inoculum. No advantage was noted with washed cell inocula.

\section{DISCUSSION}

Tests carried out between I 968 and 1975 have shown that the majority of the yeast isolates obtained from fresh strawberries, raspberries, blackberries, blackcurrants, loganberries and gooseberries utilize myo-inositol as the sole source of carbon or form red-pigmented colonies. These yeasts are rarely fermentative, sporogenous or filamentous and are identified largely on the basis of the results of nutritional tests. Maximum separation of the species can be achieved by testing with only nine of the 37 carbon sources used by Wickerham (I95I) provided that growth due to impurities in the media is reduced to acceptably low levels. When tested in this way, the identification of these species depends greatly upon the accuracy of the results of the nutritional tests and demands media free of traces of extraneous nitrogen and carbon sources. When solid media are used, the gelling agent must also be free of utilizable nitrogen or carbon. Carbon source impurities have been reported in commercially available maltose and melezitose (Buhagiar \& Barnett, I97I) and D-galactose (Shifrine, Phaff \& Demain, I954), and van der Walt (1970) states that certain oligosaccharides such as sucrose and maltose may undergo slow hydrolysis after prolonged storage in basal medium. Shifrine et al. (1954) treated a suspension of D-galactose with washed cells of Candida 
monosa (C. krusei) to remove the sugar contaminants and then added the purified D-galactose to the basal utilization medium which was subsequently gelled with washed agar. The present experiments have shown that media solidified with deionized Ludox HS-40 have marked advantages over media solidified with washed or unwashed commercial agars. With Ludox HS-40 media, utilization of a substrate could be clearly distinguished from growth resulting from contaminating constituents in the agars tested. Silica gel prepared from several starting materials, including Ludox, is subject to influences such as temperature, silica content, $\mathrm{pH}$, nature of ions present and method of sterilization. It is necessary at times to vary these factors empirically to obtain satisfactory media. The deionized Ludox HS-40 tested has advantages over the silica solutions used by other workers (Ingelman \& Laurell, I947; Temple, I949; Taylor, I950; Kingsbury \& Barghoorn, I954) in that the gelling time is predictable, it does not gel on autoclaving, it is non-toxic to all the yeasts tested and can be stored for lengthy periods. All the yeasts tested grew on media containing concentrations of $\mathrm{KH}_{2} \mathrm{PO}_{4}$ and $\mathrm{NaCl}$ Io times higher than those recommended by Wickerham ( $195 \mathrm{I}$ ), and, if required, the gelling time can be reduced by increasing the concentration of these salts to at least those levels.

Since gelling with deionized Ludox HS-40 is independent of heat, the automatic dispensing of media in large batches is clearly facilitated. Unlike agar media, however, thinly spread silica gel medium is normally subject to shrinkage and fragmentation. With Repli dishes this problem was avoided by dispensing $3 \mathrm{ml}$ amounts into each compartment. The blocks of media $(20 \times 20 \times 7 \mathrm{~mm})$ rarely showed any shrinkage, fragmentation or condensation in sealed Repli dishes stored for 6 months at $20^{\circ} \mathrm{C}$.

The author wishes to thank E. I. du Pont de Nemours \& Co. for their co-operation and for supplying the samples of Ludox HS-40, Dr C. Dennis for criticisms of the manuscript, Mr B. J. H. Stevens for estimations of sugar levels and for deionizing the Ludox HS-40, Mrs H. A. Belcher for her invaluable technical assistance and $\mathrm{Mr}$ M. J. Brown for the production of the photographic plate.

\section{REFERENCES}

BarnetT, J. A. \& Ingram, M. (I955). Technique in the study of yeast assimilation reactions. Journal of Applied Bacteriology 18, I3I-I48.

BuHAGIAR, R. W. M. \& BARNETT, J. A. (I97I). The yeasts of strawberries. Journal of Applied Bacteriology 34, 727-739.

Hirs, C. H. W., Moore, S. \& Stein, W. H. (1952). Isolation of amino acids by chromatography on ion exchange columns; use of volatile buffers. Journal of Biological Chemistry 195, 669-683.

INGELMAN, B. \& LAURELL, H. (1947). The preparation of silicic acid jellies for the cultivation of microorganisms. Journal of Bacteriology 53, 364-365.

KingSBURY, J. M. \& BARGHOORN, E. S. (I954). Silica gel as a microbiological medium: potentialities and a new method of preparation. Applied Microbiology 2, 5-8.

KLotzsch, H. \& BerGMeYeR, H. U. (1963). D-Fructose. In Methods of Enzymatic Analysis, pp. 156-159. Edited by H. U. Bergmeyer. New York and London: Academic Press.

Shifrine, M., Phaff, H. J. \& Demain, A. L. (1954). Determination of carbon assimilation patterns of yeasts by replica plating. Journal of Bacteriology 68, 28-35.

Slein, M. W. (1963). D-Glucose. Determination with hexokinase and glucose-6-phosphate dehydrogenase. In Methods of Enzymatic Analysis, pp. I 17-123. Edited by H. U. Bergmeyer. New York and London: Academic Press.

STEVEN, F. S. \& TRISTRAM, G. R. (1962). The presence in commercial sulphonated-polystyrene resins of some amino acids. Biochemical Journal 83, 245.

TAYLOR, C. B. (1950). An improved method for the preparation of silica gel media for microbiological purposes. Journal of General Microbiology 4, 235-237. 
TeMPLE, K. L. (1949). A new method for the preparation of silica gel plates. Journal of Bacteriology 57, 383.

THORNE, R. S. W. (1945). Recent work on the nitrogen nutrition of yeast. Journal of the Institute of Brewing 5I, II4-I 26.

vaN DER WALT, J. P. (1970). Criteria and methods used in classification. In The Yeasts. A Taxonomic Study, Edited by J. Lodder. Amsterdam: North-Holland Publishing Co.

Wickerham, L. J. (195I). Taxonomy of yeasts. United States Department of Agriculture Technical Bulletin, no. $1029, \mathrm{I}-56$. 